\title{
Outcome of Anterior Cervical Discectomy with PEEK Cage Fixation for Single Level Cervical Disc Disease
}

\author{
SAJID KHAN, AKRAMULLAH, MUSAWER KHAN, RAMZAN HUSSAIN, MUMTAZ ALI \\ Prime Teaching Hospital, Peshawar Medical College, Irfan General Hospital, Peshawar - Pakistan \\ DOI 10.36552/pjns.v24i2.397
}

\begin{abstract}
Objective: To assess the outcome of anterior cervical discectomy and fusion (ACDF) with PEEK cage.

Material and Methods: This prospective study was conducted in the Departments of Neurosurgery Prime Teaching Hospital and Irfan General Hospital Peshawar. Patients undergoing one level ACDF with PEEK cage fixation were enrolled in the study. Patients who needed multiple level ACDF or corpectomy with plating and redo cases were excluded from the study. A proforma, which included age, gender, address, level of prolapsed disc, sign and symptoms, pain score, MRI findings were filled. All patients were assessed on day of discharge and on follow-up visit after one month. Data was analyzed with SPSS version 22.
\end{abstract}

Results: Total 95 patients were included out of which 58 (61\%) were male and 37 (39\%) were female. Range of patients`Age was from 27 years to 64 years with 50.4 years mean age. Most patients (65\%) had C6 radiculopathy. 58 patients (61\%) had right sided radicular pain. 5 patients (5.26\%) had radiculomyelopathy. C5 - C6 was the most common level operated (68 patients). Excellent results were achieved in 75 patients (79\%) while satisfactory results in the rest of patients using Odom's criteria. Bony fusion occurred in $92 \%$ of patients at 6 months.

Conclusion: $A C D F$ with PEEK cage fixation is a safe and beneficial procedure in one level cervical prolapse disc disease.

Keywords: Anterior cervical discectomy and fusion, PEEK (polyether ether ketone) cage, radiculopathy, radiculomyelopathy.

\section{INTRODUCTION}

Cervical disc prolapse is a common disorder in neurosurgery practice. ${ }^{1}$ Common presentation of which is radiculopathy with an incidence of 1.79 per 1000 persons per year. ${ }^{2}$ Common modality of investigation in symptomatic patients is MRI cervical spine. ${ }^{3}$ Most of these patients can be managed with conservative treatment, however, patients with severe symptoms and prolonged duration or any neurological deficit need surgery. ${ }^{4}$ Different approaches have gained wide acceptance in neurosurgery of which Cloward and Smith Robinson are notable. ${ }^{5,6}$ Anterior cervical discectomy with or without fusion is a topic of controversy due to lack of multicentric randomized controlled trials. ${ }^{5}$ Iliac crest graft (autologous bone) has been used for fusion, but due to donor site morbidity and graft collapse have lead the surgeons to use titanium and PEEK cages for fusion. ${ }^{6,7}$ While both these cages are in wide usage, PEEK cage has high rates of fusion and maintenance of cervical disc height. ${ }^{7}$ The use of cervical plates has demonstrated increased fusion rates in comparison to ACDF without cervical plate's augmentation. ${ }^{8}$ In this study, we share our two years' experience of anterior cervical discectomies with PEEK cage and fixation with mini plates. 


\section{MATERIAL AND METHODS}

\section{Study Design}

This Prospective study was performed at the Departments of Neurosurgery Prime Teaching Hospital and Irfan General Hospital Peshawar from 15 November 2017 to 15 November 2019.

\section{Inclusion Criteria}

After taking approval from ethical committee and taking consent from Patients having radiculopathy or radiculomyelopathy due to single level cervical disc prolapse that underwent anterior cervical discectomy with peek cage fixation were included in this study.

\section{Exclusion Criteria}

Patients who needed two or more level ACDF and corpectomy with plating were not included in the study. Patients operated for the second time and other patients who needed posterior stabilization after ACDF with PEEK cage fixation were also excluded from this study.

\section{Data Analysis}

Data was collected on a proforma containing age, gender, sign and symptoms, level of prolapsed disc on MRI cervical spine and comorbidities. These patients were assessed again on the day of discharge and after 1month using visual analogue score for pain and improvement using Odom's criteria. Fusion was assessed by lateral x-ray of cervical spine. Data was analyzed using SPSS version 21.

\section{Surgical Technique}

All patients were positioned supine after general anesthesia. Sand bag was placed under the shoulders and Halter traction applied. Adhesive taps were used to pull down shoulders to get a clear lateral $\mathrm{x}$-ray cspine. A horizontal skin incision was given and platysma muscle was cut. A plan of dissection was made medial to sternocleidomastoid and carotid artery was approached. Further dissection was carried out medial to the carotid artery and lateral to the trachea. Longus colli muscles on both sides of vertebral body were exposed. LP needle was used to identify the level. Microscope was introduced. Intervertebral distractor was used in all cases. Intervertebral disc and any osteophyte if present were removed using high speed drill, curettes, 1-mm kerrison rongeur and pituitary rongeur. Posterior intervertebral fascia was excised to see the Dura. After complete decompression, a PEEK cage with autologous bone graft was inserted into the disc space and micro plates were fixed on to this. After this wound, was irrigated and closed in layers. All patients used Philadelphia collar in post-operative period.

\section{RESULTS}

\section{Gender Incidence}

Total 95 patients undergone anterior cervical discectomy with PEEK cage fixation during our study period 58 were male $(61 \%)$ and 37 were female $(39 \%)$.

\section{Age Incidence}

Patients`age was ranging from 27 to 64 years, with 50.4 years as mean.
Table 1: Frequency of Cervical Nerve Roots Involvement.

\begin{tabular}{|l|l|r|r|}
\hline $\begin{array}{l}\text { Neurological Intact } \\
\text { Patient }\end{array}$ & No Sensory or Motor Deficit & 12 & $12.6 \%$ \\
\hline & C6 dermatome & 51 & $53.7 \%$ \\
Sensory Deficit & C7 dermatome & 13 & $13.7 \%$ \\
& C5 dermatome & 9 & $9.47 \%$ \\
& C4 dermatome & 6 & $6.31 \%$ \\
& T1 dermatome & 4 & $4.21 \%$ \\
\hline & Deltoid (C5 nerve root) & $3.15 \%$ \\
Motor Deficit & Biceps, forearm flexion (C6 nerve root) & 22 & $23.15 \%$ \\
& Triceps, forearm extension (C7 nerve root) & 16 & $16.84 \%$ \\
& Hand intrinsic (C8 \& T1 nerve root) & 7 & $7.37 \%$ \\
\hline \multirow{3}{*}{ Absent or } & Biceps & 14 & $14.73 \%$ \\
Diminished Reflexes & Brachioradialis & 18 & $18.94 \%$ \\
& Triceps & 15 & $15.79 \%$ \\
\hline
\end{tabular}

\section{Clinical Presentation}

Most patients had C6 radiculopathy followed by $\mathrm{C} 7$ radiculopathy (Table 1). Radicular pain was more on the right side in 62 patients $(65.26 \%)$. Spurling sign was positive in 35 patients (36.84\%), while the Hoffmann sign was positive in 4 patients (4.21\%).

Pain score was $7 / 10$ or above on the visual analogue score in 37 $(38.95 \%)$ patients. 5 patients had radiculomyelopathy. Myelopathy 
was graded using Nurick grading (2 patients were grade 2, 2 were grade 3 and 1 patient was grade 4 ). The outcome was assessed by using Odom's criteria and visual analogue score for arm and neck pain. All surgeries were performed by the same surgical team. Duration of surgery was 2 to 3 hours, with a mean of140 minutes. Most common level operated was C5 C6 (68 patients, $71.57 \%$ ), followed by C6 - C7 (13 patients $13.68 \%), \mathrm{C} 4-\mathrm{C} 5$ (9patients, 9.7\%), C3 - C4 (2 patients, 2.1\%) and C7 - T1 (3 patients, 3.15\%). When these patients were assessed at discharge and after 1 month post operatively, following results were obtained (see table 2). Fusion was assessed using lateral $\mathrm{x}$-ray cervical spine for bridging trabecular bone and the absence of radiolucent gap. Flexion and extension cervical spine $\mathrm{x}$-ray were also taken to see any motion between vertebral bodies and interspinous gap. Fusion rate was $92 \%$ at 6 months. An interspinous gap of $\leq 1 \mathrm{~mm}$ difference on flexion and extension $\mathrm{x}$ ray was considered good fusion.

Table 2: Outcome based on Odom's Criteria after.

\begin{tabular}{|l|l|c|}
\hline Excellent & $\begin{array}{l}\text { Improvement in every preoperative } \\
\text { symptom and sign }\end{array}$ & $75(79 \%)$ \\
\hline Good & $\begin{array}{l}\text { Persistence of minimal preoperative } \\
\text { symptoms (No symptoms except } \\
\text { tenderness in neck). Improved } \\
\text { Abnormal findings. }\end{array}$ & $16(16.8 \%)$ \\
\hline Poor & $\begin{array}{l}\text { Definite improvement in some } \\
\text { preoperative symptoms, others } \\
\text { slightly improved(residual root } \\
\text { irritation with transient pain) }\end{array}$ & $4(4.21 \%)$ \\
\hline & $\begin{array}{l}\text { No change or worsening of } \\
\text { Symptoms and signs. }\end{array}$ & $0(0 \%)$ \\
\hline
\end{tabular}

Apart from difficult intubation, no other intraoperative complication (surgery or anesthesia related) was noted. Dysphagia was the most common post-operative complication followed by subcutaneous hematoma and wound infection.

Table 3: Post-operative Complications.

\begin{tabular}{|l|l|}
\hline Dysphagia & $15(15.8 \%)$ \\
\hline Post-operative hematoma & $4(4.21 \%)$ \\
\hline Wound infection & $1(1.05 \%)$ \\
\hline Horner syndrome & $1(1.05 \%)$ \\
\hline $\begin{array}{l}\text { Dural tear, recurrent laryngeal nerve injury, } \\
\text { esophageal injury }\end{array}$ & $0(0 \%)$ \\
\hline
\end{tabular}

\section{DISCUSSION}

Anterior cervical discectomy with and without fusion has been a work horse for cervical disc diseases ${ }^{9,10}$. Initially iliac crest and fibular autologous bone graft alone were used for fusion without plating ${ }^{11}$ but fusions rates were better with usage of anterior cervical plates, which lead the neurosurgeons to use these for single and multiple level discectomies ${ }^{12,13}$. Significant donor site morbidity and graft collapse resulted in introduction of titanium and PEEK cages for fusion ${ }^{12,13}$. The efficacy of both these implants is well established with slightly better results for PEEK cages $^{14-16}$.

Use of titanium and peek cage has increased the fusion rates with good postoperative pain relief ${ }^{14,17}$, but recently, the use of titanium cage has been discouraged $^{14}$. Cho et al has published their experience of Peek cage for ACDF compared to autologous bone graft for single and multiple level disc diseases. The results with peek cage are superior in terms of bony fusion, disc height maintenance and good neurological outcome $^{18,19}$. In another paper Cho et al examined the effectiveness of PEEK cages compared to autologous iliac crest graft with and without plating. Results are favorable for PEEK cage and autologous bone graft with plating for single and multiple level anterior cervical discectomies and fusion. PEEK cages have lesser complications and less blood loss compared to Autologous iliac bone graft ${ }^{20}$.

In our study, most patients had C6 radiculopathy and most common level of surgery is C5-C6 followed by $\mathrm{C} 6-\mathrm{C} 7$ which are similar to that Ofchen et $\mathrm{al}^{20}$. Our Outcome in terms of pain relief and symptomatic improvement based on Odom's criteria is comparable to study undertaken by L. Mastronadi et $\mathrm{al}^{21}$. Excellent results were achieved in $79 \%$ compared to their $80.5 \%$ and good results in $16.7 \%$ to their $16 \%$.

Fusion rates of $92 \%$ at 6 months in our study are comparable to $93.33 \%$ in the study undertaken by Kulkarni at National university Hospital, Singapore ${ }^{22}$. Fusion was assessed on radiological criteria as mentioned in the result section, though our study was mainly focused on outcome based on Odom's criteria.

Post-operative complications in our study were transient dysphagia (15.8\%), wound hematoma $(4.21 \%)$ and wound infection $(1.05 \%)$. These are comparable to another study by Fountas et al where these complications are 9.5\%, 5.6\% and $0.1 \%$ respectively ${ }^{23}$. Other less common complication of 
Dural tear, recurrent laryngeal nerve palsy and esophageal perforation in their series doesn't occur in our study and it may be due to large sample size of their study (1015 patients compared to our 95 patients).

\section{CONCLUSION}

Management of Cervical disc disease has gone through a historic evolution. Even today different surgical techniques and material for bone fusion is used. Anterior cervical discectomy with PEEK cage fixation is an effective and safe treatment option for single level cervical disc disease with good outcome regarding pain and neurological functions.

\section{REFERENCES}

1. Radhakrishnan K, Litchy WJ, O'Fallon WM, Kurland LT. Epidemiology of cervical radiculopathy A population-based study from Rochester, Minnesota, 1976 through 1990. Brain, 1994; 117 (2): 325-35.

2. Schoenfeld AJ, George AA, Bader JO, Caram PMJ. Incidence and Epidemiology of Cervical Radiculopathy in the United States Military: 2000 to 2009. Clin Spine Surg. 2012; 25 (1): 17.

3. Modic MT, Masaryk TJ, Ross JS, Carter JR. Imaging of degenerative disk disease. Radiology, 1988; 168 (1): 177-186. Doi: 10.1148/radiology.168.1.3289089.

4. Lunsford LD, Bissonette DJ, Jannetta PJ, Sheptak PE, Zorub DS. Anterior surgery for cervical disc disease: Part 1: Treatment of lateral cervical disc herniation in 253 cases. J Neurosurg. 1980; 53 (1): 1-11.

5. Hauerberg J, Kosteljanetz M, Bøge-Rasmussen T, Dons K, Gideon P, Springborg JB, et al. Anterior Cervical Discectomy With or Without Fusion With Ray Titanium Cage: A Prospective Randomized Clinical Study. Spine, 2008; 33 (5): 458.

6. Niu C-C, Liao J-C, Chen W-J, Chen L-H. Outcomes of Interbody Fusion Cages Used in 1 and 2-levels Anterior Cervical Discectomy and Fusion: Titanium Cages Versus Polyetheretherketone (PEEK) Cages. Clin Spine Surg. 2010; 23 (5): 310.

7. Niu C-C, Liao J-C, Chen W-J, Chen L-H. Outcomes of interbody fusion cages used in 1 and 2-levels anterior cervical discectomy and fusion: titanium cages versus polyetheretherketone (PEEK) cages. Clin Spine Surg. 2010; 23 (5): 310-316.

8. Wang JC, McDonough PW, Endow KK, Delamarter RB. Increased Fusion Rates With Cervical Plating for Two-Level Anterior Cervical Discectomy and Fusion. Spine, 2000; 25 (1): 41.

9. Bohlman HH, Emery SE, Goodfellow DB, Jones PK. Robinson anterior cervical discectomy and arthrodesis for cervical radiculopathy. Long-term follow-up of one hundred and twenty-two patients. J Bone Joint Surg Am. 1993; 75 (9): 1298-307.

10. Brodke DS, Zdeblick TA. Modified Smith-Robinson procedure for anterior cervical discectomy and fusion. Spine, 1992; 17 (10 Suppl): S427-30.

11. Young WF, Rosenwasser RH. An early comparative analysis of the use of fibular allograft versus autologous iliac crest graft for interbody fusion after anterior cervical discectomy. Spine, 1993; 18 (9): 1123-4.

12. Silber JS, Anderson DG, Daffner SD, Brislin BT, Leland JM, Hilibrand AS, et al. Donor Site Morbidity After Anterior Iliac Crest Bone Harvest for SingleLevel Anterior Cervical Discectomy and Fusion. Spine, 2003; 28 (2): 134.

13. Niu C-C, Liao J-C, Chen W-J, Chen L-H. Outcomes of interbody fusion cages used in 1 and 2-levels anterior cervical discectomy and fusion: titanium cages versus polyetheretherketone (PEEK) cages. Clin Spine Surg. 2010; 23 (5): 310-316.

14. Chou Y-C, Chen D-C, Hsieh WA, Chen W-F, Yen P-S, Harnod T, et al. Efficacy of anterior cervical fusion: comparison of titanium cages, polyetheretherketone (PEEK) cages and autogenous bone grafts. J Clin Neurosci. 2008; 15 (11): 1240-1245.

15. Kersten RFMR, van Gaalen SM, de GastA, Öner FC. Polyetheretherketone (PEEK) cages in cervical applications: a systematic review. Spine J. 2015; 15 (6): 1446-1460.

16. Ha S-K, Park J-Y, Kim S-H, Lim D-J, Kim S-D, Lee S$\mathrm{K}$. Radiologic assessment of subsidence in stand-alone cervical polyetheretherketone (PEEK) cage. J Korean Neurosurg Soc. 2008; 44 (6): 370.

17. Chen Y, Wang X, Lu X, Yang L, Yang H, Yuan W, et al. Comparison of titanium and polyetheretherketone (PEEK) cages in the surgical treatment of multilevel cervical spondylotic myelopathy: a prospective, randomized, control study with over 7-year follow-up. Eur Spine J. 2013; 22 (7): 1539-46.

18. Cho D-Y, Liau W-R, Lee W-Y, Liu J-T, Chiu C-L, Sheu P-C. Preliminary Experience Using a Polyetheretherketone (PEEK) Cage in the Treatment of Cervical Disc Disease. Neurosurgery, 2002; 51 (6): 1343-50.

19. Cho D-Y, Lee W-Y, Sheu P-C. Treatment of multilevel cervical fusion with cages. Surg Neurol. 2004; 62 (5): 378-85.

20. Chen, Jyi-Feng \& Wu, Chieh-Tsai \& Lee, Sai-Cheung \& Lee, Shih-Tseng. Use of a polymethylmethacrylate cervical cage in the treatment of single-level cervical disc disease. Journal of neurosurgery. Spine, 2005; 3 : 24-8. 10.3171/spi.2005.3.1.0024.

21. Mastronardi L, Ducati A, Ferrante L. Anterior cervical fusion with polyetheretherketone (PEEK) cages in the treatment of degenerative disc disease. Preliminary 
observations in 36 consecutive cases with a minimum 12-month follow-up. Acta Neurochir (Wien), 2006; 148 (3): 307-12.

22. Kulkarni AG, Hee HT, Wong HK. Solis cage (PEEK) for anterior cervical fusion: preliminary radiological results with emphasis on fusion and subsidence. Spine

$$
\text { J. 2007; } 7 \text { (2): 205-9. }
$$

23. Fountas APA, Kostas N, Kapsalaki, Eftychia Z, Nikolakakos, Leonidas G et al. Cervical Discectomy and Fusion Associated Complications, Spine, 2007; 32 (21): 2310-2317.

\section{Additional Information}

Disclosures: Authors report no conflict of interest.

Ethical Review Board Approval: The study was conformed to the ethical review board requirements.

Human Subjects: Consent was obtained by all patients/participants in this study.

Conflicts of Interest:

In compliance with the ICMJE uniform disclosure form, all authors declare the following:

Financial Relationships: All authors have declared that they have no financial relationships at present or within the previous three years with any organizations that might have an interest in the submitted work.

Other Relationships: All authors have declared that there are no other relationships or activities that could appear to have influenced the submitted work.

Address for Correspondence:

Sajid Khan

Prime Teaching Hospital, Peshawar, Pakistan

Email:utmanxai@gmail.com

\section{AUTHORSHIP AND CONTRIBUTION DECLARATION}

\begin{tabular}{|l|l|l|}
\hline Sr.\# & Author's Full Name & Intellectual/Contribution to Paper in Terms of: \\
\hline 1. & Sajid Khan & 1. Main investigator/ data collection. \\
\cline { 1 - 2 } 2. & Akramullah & 2. Data analysis and report writing \\
\cline { 1 - 2 } 3. & Musawer Khan & 3. Literature review and Manuscript writing \\
\cline { 1 - 2 } 4. & Ramzan Hussain & 4. Co investigator and data collector. \\
\cline { 1 - 2 } 5. & Mumtaz Ali & 5. Literature review and Manuscript writing \\
\hline
\end{tabular}

Date of Submission: 20-2-2020

Date of Revision: 5-04-2020

Date of Online Publishing: 30-06-2020

Date of Print: 30-07-2020 